Acta vet. scand. 1970, 11, 491-493.

Brief Communication

\title{
EXAMINATION OF THE HAIR CUTICLE BY DIFFERENTIAL INTERFERENCE MICROSCOPY
}

Species identification of mammalian hairs most often includes a morphological examination of the hair cuticle for classification of the scale pattern. Several techniques have been used for this purpose including microscopy of cuticula impressions in gelatine or cellulose-acetate (Loske 1964) and direct microscopy of hairs by use of incident illumination (Ewans 1963/64). A combination of these two methods has not previously been described as far as known to the author.

Single hairs from the outer coats from dog, cat, cow and horse were examined by means of differential interference microscopy of cuticula impressions made by semi-embedding of the hair in a mixture of nitrocellulose and polyvinylacetate in the form of a commercial glue ${ }^{\star}$ ). A drop of this glue was spread into a thin film by means of a razor blade upon a microscope slide, on which the hair was stretched after being cleaned in alcohol and ether. After approx. $15 \mathrm{~min}$. when the glue was dry the hair was removed leaving impressions of the cuticula in the film.

The cuticula impressions were examined in a Nikon differential interference microscope model $R$. The object is illuminated by coherent rays of polarized light vibrating perpendicularly to each other and laterally displaced from each other. This forms the basis for a shearing effect which enables a highly differentiated study of surface structures.

The cuticula impressions were photomicrographed with a Nikon microflex model PFM. An Ilford FP4- $36 \mathrm{~mm} 22$ DIN film was used, exposure time approx. 5 sec., transformer voltage 8 , and the field diaphragm closed down at maximum without disturbing the finder mask of the view field.

As shown in Fig. 1 the method described provides an almost perfect view of the cuticula scale pattern. However, a disadvantage is that the hair may be damaged to such an extent that

*) Lyma A lim. A/S Lyma Lim fabrikker. 


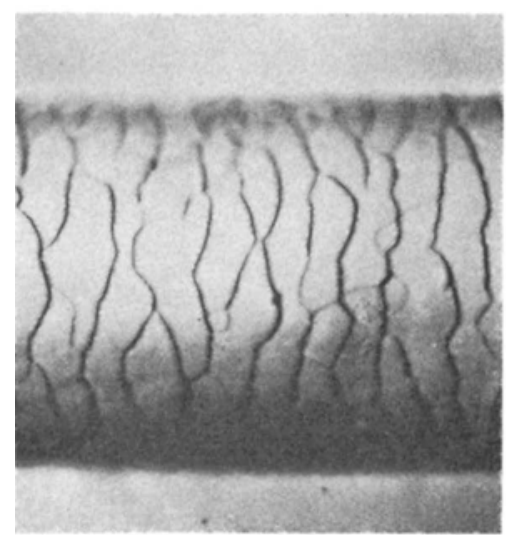

$a$

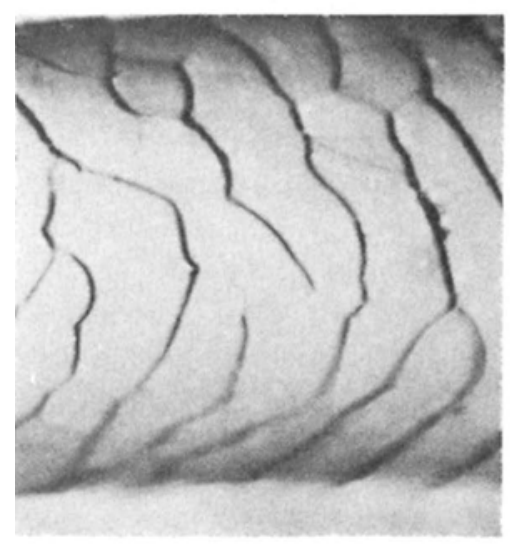

c

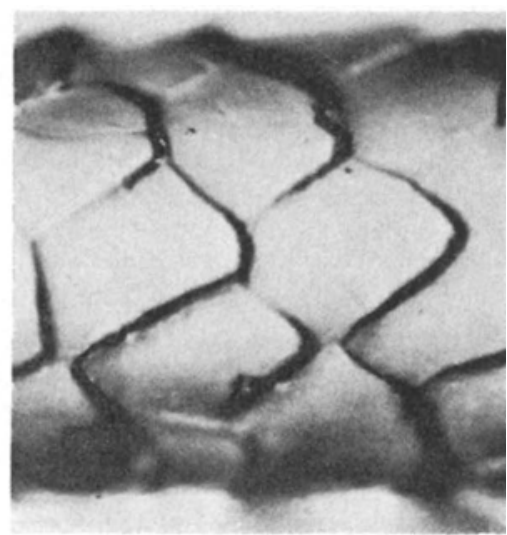

b

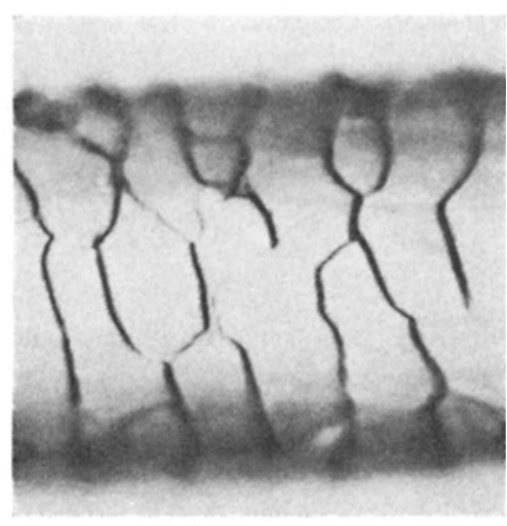

d

Fig u r e 1. Cuticula scale patterns of canine (a), feline (b), bovine (c) and equine (d) hairs. a: $200 \times$, b, c, d: $400 \times$.

further examination is made impossible. Therefore, when only one or a few hairs are available it is recommended not to use the embedding technique but the direct microscopy of the hair in the differential interference microscope, which gives an acceptable view of the cuticula scale pattern.

\section{H. B. Simonsen}

The Department of Forensic and State Veterinary Medicine, Royal Veterinary and Agricultural University, Copenhagen, Denmark. 


\section{REFERENCES}

Loske, Th.: Methoden der Textilmikroskopie. (Methods of textile microscopy). Komos. Gesellschaft der Naturfreunde. Franckh'sche Verlagshandlung, Stuttgart 1964.

Ewans, W. E. D.: The use of normal incident illumination in the examination of hair cuticle. J. forensic Sci. Soc. 1963/64, 4, 217218.

(Received August 31, 1970). 


